\title{
Prevalence of Intestinal Parasitic Infections and Related Risk Factors among Street Dwellers in Addis Ababa, Ethiopia
}

\author{
Banchiamlak Mekonnen ${ }^{1}$, Berhanu Erko ${ }^{2}$ and Mengistu Legesse ${ }^{2^{*}}$ \\ ${ }^{1}$ Amhara Regional Health Office, Bahir Dar, Ethiopia \\ ${ }^{2}$ Aklilu Lemma Institute of Pathobiology, Addis Ababa University, Addis Ababa, Ethiopia
}

"Corresponding author: Mengistu Legesse, Aklilu Lemma Institute of Pathobiology, Addis Ababa University, P.O. Box, 1176, Addis Ababa, Ethiopia, Tel: 251112763091; Fax: 251112755296; E-mail: dlegessem@yahoo.com

Rec date: Jan 31, 2014, Acc date: Mar 05, 2014, Pub date: Mar 07, 2014

Copyright:@ 2013 Mekonnen, et al. This is an open-access article distributed under the terms of the Creative Commons Attribution License, which permits unrestricted use, distribution, and reproduction in any medium, provided the original author and source are credited.

\begin{abstract}
Background: Epidemiological information on the prevalence of various intestinal parasitic infections in different sectors of the society and localities is very important to develop appropriate control strategies. Many studies have been conducted to determine the prevalence of intestinal parasitic infections in Ethiopia. However, studies pertaining to the prevalence of intestinal parasitic infections among the street dwellers are limited. Therefore, the aim of this study was to determine the prevalence of intestinal parasites and associated risk factors among street dwellers in Addis Ababa.
\end{abstract}

Method: A cross-sectional parasitological survey was conducted among street dwellers in Addis Ababa, between October 2012 and March 2013. Fresh stool samples were collected from the participants and processed by direct microscopy, concentration, and Kato-Katz thick smear methods. The participants were also interviewed about knowledge of intestinal parasites and risk factors for intestinal parasitic infections using structured questionnaire.

Results: A total of 355 participants, $312(87.89 \%)$ males and $43(12.11 \%)$ females participated in the study. The mean age of the study participants was $28.4+12.4$ years (age ranged from 4 to 75 years). Nine species of intestinal parasites were identified with an overall prevalence of $71.8 \%$. The most prevalent parasites were Ascaris lumbricoides (34.9\%), Trichuris trichiura (22.8\%), Giardia lamblia (9.6\%) and Entamoeba histolytica/dispar (8.2\%). Two thirds $(67.1 \%)$ of the participants responded that they had no adequate information about intestinal parasites. Consumption of leftover fruit was significantly associated with high prevalence of intestinal parasitic infections (adjusted odds ratio $=2.9,95 \% \mathrm{Cl} ; 1.02,8.22$ ).

Conclusion: The study revealed high prevalence of intestinal parasitic infections in street dwellers in Addis Ababa. Thus, any community-based intervention program of intestinal parasites should consider these segments of population, since they contribute to the source of intestinal parasitic infections for the community.

Keywords: Intestinal parasites; Street dwellers; Ethiopia

\section{Abbreviations}

WHO: World Health Organization; FMoH: Federal Ministry of Health; NTD: Neglected Tropical Disease; UNICEF: United Nations Children's Fund; UNECA: United Nations Economic Commission for Africa; IRB: Institutional Review Board; ALPB: Aklilu Lemma Institute of Pathobiology; SD: Standard Deviation

\section{Background}

Intestinal parasites cause considerable morbidity and mortality, especially in developing countries [1,2]. However, they are more prevalent among people who have less access to health care services and socio-economic problems. According to World Health Organization (WHO) prevention and control of intestinal parasitic infections constitute several activities including universal or selective deworming of population groups that are at risk of developing morbidity and chronic diseases, improving environmental sanitation, personal hygiene, food and water hygiene and appropriate health education [3]. The use of water and soap or similar agents is critical for effective removal of parasite ova/cysts from contaminated hands. However, the use of soap is determined by economic and logistic factors, and also by the perception of what is dirty and what is not [4].

Homelessness/street dwellers are an increasing problem worldwide. Approximately, there are about 500 million people in the world who are homeless. Homeless people are highly affected by low socioeconomic conditions, poor personal and environmental hygiene, and have limited access to clean water. The health problems of the homeless people are broad and they are at high risk for acute and chronic medical illnesses [2-5]. Homeless people have poor access to healthcare services [6], and those who visit health facilities may also encounter problems such as denial of treatment by providers due to their financial problem, neglect of service providers for services, and an inappropriate service-delivery time for them [7]. Study also suggests that homeless persons are marginalized group of people who cannot access conventional health care services due to the financial and time constraints linked to their livelihoods [8]. Hence, they remain as reservoir for infectious diseases transmission even in countries where there is an effective disease control. 
Although the Ethiopian government has been working to change the life style of street dwellers, the number of street dwellers has been increasing in Addis Ababa because of different reasons like individuals migration to this city from different regions of the country for job opportunity, family, social or health problems. The street dwellers sleep on streets, around bus stations, parks, open spaces, religious centers, construction sites, around graveyards, and other public places. Although it is uncertain to get the exact number of street dwellers in Addis Ababa, it is estimated at more than 100,000 (http:// www.irinnews.org).

In Ethiopia, as in many other sub-Saharan African countries, parasitic infections are widely distributed and affect various segments of the population [9-12]. However, there is little information on the prevalence of intestinal parasites among street dwellers [13]. At present, the Federal Ministry of Health (FMoH) of Ethiopia has prioritized intestinal parasitic infection as one of the Neglected Tropical Diseases (NTDs) in the National Master Plan of NTDs, and planned to develop a sustainable well integrated nation-wide surveillance, operational research and control program that would enable the country to address the public health problems due to NTDs [14]. In an effort to contribute to the control of intestinal parasitic infections, we conducted this study to provide data on the prevalence of intestinal parasites in street dwelling individuals in Addis Ababa, Ethiopia.

\section{Materials and Methods}

\section{Study population and setting}

Between October 2012 and March 2013, a cross-sectional parasitological survey was conducted in street dwellers in Addis Ababa, the capital city of Ethiopia. The number of population in Addis Ababa has increased rapidly since people migrate to the City from different regions of the country for job opportunity. According to UNICEF estimation, there are more than 100,000 street dwellers in Addis Ababa (http://www.irinnews.org) [15]. The City also hosts international institutions such as the headquarters of the United Nations Economic Commission for Africa (UNECA) and numerous other continental and international organizations. However, basic facilities such as housing, safe drinking water, toilet services, energy and sanitation/appropriate solid waste disposal services are still incompatible with the need of the people of Addis Ababa. According to the 2007 national census, $98.64 \%$ of the housing units of Addis Ababa had access to safe drinking water, while $14.9 \%$ had flush toilets, $70.7 \%$ pit toilets and $14.3 \%$ had no toilet facilities [16]. In the city, around 70 public toilets are available to those who do not have domestic toilet facilities. However, the public toilets are not evenly distributed in the City and most of them are not accessible to the inhabitants. Thus, all available vacant spaces within the City (green areas, road sides and riverbanks) are common defecation sites especially for street dwellers.

\section{Sample size estimation, data collection and examination}

The sample size was estimated using a single population proportion formula with $95 \%$ confidence, assuming an overall prevalence of $67 \%$ for parasitic infections among the target study population [13] 5\% of margin of error and 10\% non-response rate. Thus, a total of 374 participants (age 2 years and above, who had no mental problem, who were volunteers to participate and give their consent and children who had guardians/parents) were estimated to be included in the study.
Pre-survey visit was made to see the place, the number of street dwellers in selected areas and the convenient time for data collection. Then, all the street dwellers who were living in the selected areas were approached to participate in the study until the required sample size was obtained. After the aim of the survey was explained to each participant/guardian, the participants were interviewed about intestinal parasites, types of toilets utilization, source of drinking water, source of food and feeding habit using pre-tested structured questionnaire. In case of children younger than 15 years, their parents/ guardians were interviewed. Information on socio-demographic characteristics of the individuals was also included in the questionnaire. Following the interview, each participant and/or guardian was instructed on how to provide a stool sample and a coded plastic sheet was distributed to provide fresh stool sample on the next morning. The samples were transported to laboratory under a cold condition on the same morning and a portion of the stool was preserved in $10 \%$ formalin, while the rest was processed by direct and Kato-Katz thick smear methods as previously described [17]. The direct wet mount of stool was examined for the presence of eggs and motile trophozoites under light microscope, while the Kato-Katz thick smear and concentration methods were used for detection of helminth eggs and protozoan cysts [18].

\section{Ethical Consideration}

The study was conducted after obtaining ethical approval from the Institutional Review Board (IRB) of the Aklilu Lemma Institute of Pathobiology (ALIPB), Addis Ababa University. Verbal consent was obtained from each study participant/parent. Participants were also informed that all personal information is treated strictly confidential. Study participants found positive for intestinal parasites were treated for free using standard drugs by nurse.

\section{Data Analysis}

Data was computerized using Epi Data version 3.1 and analyzed using SPSS version 21.0. Different variables were summarized using frequency tables. Association between the dependent and independent variables were assessed using logistic regression analyses. Results were considered to be statistically significant when p-value was less than 0.05 .

\section{Results}

\section{Socio-demographic Characteristics of the Study Participants}

A total of 355 participants (87.9\% males and $12.1 \%$ females) provided stool samples. The mean age of the study participants was $28.4(\mathrm{SD}=12.4)$ years (age ranged from 4 to 75 years). A considerable number of the study participants (76.9\%) were illiterate. When asked what factors led them to become street dwellers, the majority of the participants (64.1\%) mentioned that they migrated from rural to Addis Ababa in search of job opportunity and about $40.3 \%$ have been living on the street for more than two years (Table 1).

\begin{tabular}{|l|l|l|}
\hline Characteristics & & Number (\%) \\
\hline \multirow{2}{*}{ Sex } & Male & $312(87.9)$ \\
\cline { 2 - 3 } & Female & $43(12.1)$ \\
\hline Age group(year) & $<20$ & $72(20.9)$ \\
\hline
\end{tabular}


Citation: Banchiamlak Mekonnen, Berhanu Erko and Mengistu Legesse (2014) Prevalence of Intestinal Parasitic Infections and Related Risk Factors among Street Dwellers in Addis Ababa, Ethiopia. J Trop Dis 2: 132. doi:10.4172/2329-891X.1000132

Page 3 of 7

\begin{tabular}{|c|c|c|}
\hline & $20-29$ & $142(40.0)$ \\
\hline & $30-39$ & $87(24.5)$ \\
\hline & $>39$ & $54(15.2)$ \\
\hline \multirow[t]{4}{*}{ Ethnicity } & Amhara & $148(42.2)$ \\
\hline & Oromo & 113(32.2) \\
\hline & Guragie & $46(13.1)$ \\
\hline & Tigrie & $44(12.5)$ \\
\hline \multirow[t]{3}{*}{ Educational level } & Illiterate & $269(76.9)$ \\
\hline & primary & $62(17.7)$ \\
\hline & secondary & $19(5.4)$ \\
\hline \multirow{6}{*}{$\begin{array}{l}\text { Factors that led to } \\
\text { street dwelling }\end{array}$} & Poverty associated & $223(62.8)$ \\
\hline & Substance abuse associated & $85(24.0)$ \\
\hline & Pear pressure associated & $12(3.4)$ \\
\hline & Divorce and family related & $11(3.1)$ \\
\hline & 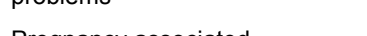 & $11(3.1)$ \\
\hline & $\begin{array}{l}\text { Pregnancy assoclated } \\
\text { Fducational problem }\end{array}$ & $6(1.7)$ \\
\hline \multirow{4}{*}{$\begin{array}{l}\text { Duration as street } \\
\text { dweller }\end{array}$} & For a month & $13(3.7)$ \\
\hline & For a year & $73(20.7)$ \\
\hline & For two years & 124(35.2) \\
\hline & For more than two years & $142(40.3)$ \\
\hline
\end{tabular}

Table 1: Socio- demographic characteristics of the study participants

\section{Intestinal parasitic infections among the participants}

Table 2 shows the prevalence of intestinal parasitic infections and the species among the study participants. In general, seven species of intestinal helminths and two species of protozoan parasites were identified with an overall prevalence of $71.8 \%$. The predominant parasite was Ascaris lumbricoides (34.9\%) followed by Trichuris trichiura (22.8\%) and Taenia species (17.5\%). Among the males, 197 $(71.2 \%)$ and among the females, 33(76.7\%) were positive at least for

\begin{tabular}{|l|l|l|}
\hline Characteristics & Number (\%) of study participants & Number (\%) positive for any parasite \\
\hline Age group (year) & & \\
\hline$<20$ & $72(20.2)$ & $55(76.4)$ \\
$20-29$ & $142(40.0)$ & $100(70.6)$ \\
$30-39$ & $87(24.5)$ & $64(73.6)$ \\
+40 & $54(15.2)$ & $36(66.7)$ \\
\hline Educational status & & \\
\hline Illiterate & $269(76.9)$ & $198(73.6)$ \\
primary & $62(17.7)$ & $43(69.4)$ \\
secondary & $19(5.4)$ & $12(63.2)$ \\
\hline Durations as street dweller & & \\
\hline For a month & $13(3.7)$ & $10(77.0)$ \\
For a year & $73(20.7)$ & $51(69.9)$ \\
For two years & $124(35.2)$ & $95(76.6)$ \\
\hline
\end{tabular}

one intestinal parasitic infection. Single parasitic infection (44.8\%) was prevalent followed by double $(22.0 \%)$, triple $(4.2 \%)$ and more than three parasites $(1.0 \%)$

\begin{tabular}{|l|l|}
\hline Parasite species & Prevalence of infection (\%) \\
\hline $\begin{array}{l}\text { Protozoa } \\
\text { Entamoeba histolytica /dispar }\end{array}$ & $29(8.2)$ \\
\hline Giardia lamblia & $34(9.6)$ \\
\hline $\begin{array}{l}\text { Helminths } \\
\text { Ascaris lumbricoides }\end{array}$ & $124(34.9)$ \\
\hline Trichuris trichiura & $81(22.8)$ \\
\hline Taenia species & $62(17.5)$ \\
\hline Strongyloides stercoralis & $19(5.4)$ \\
\hline Hymenolepis nana & $14(3.9)$ \\
\hline Hookworms & $6(1.7)$ \\
\hline Enterobius vermicularis & $4(1.1)$ \\
\hline Over all prevalence & $255(71.8)$ \\
\hline
\end{tabular}

Table 2: Prevalence of intestinal parasitic infections and species among the study participants

Table 3 shows prevalence of parasitic infections by age groups, duration of stay and educational status among the study participants. The prevalence of intestinal parasitic infections was higher $(76.4 \%)$ among children younger than 20 years though it was not statistically significant. Similarly, the prevalence of infections was higher among illiterates (73.6\%) than among primary $(69.4 \%)$ and secondary $(63.3 \%)$ schools completed individuals. Relatively higher prevalence was also observed among street dwellers who lived on the street for short durations $(77.0 \%)$ compared to among individuals who lived on the street for more than two years $(68.0 \%)$. 
Citation: Banchiamlak Mekonnen, Berhanu Erko and Mengistu Legesse (2014) Prevalence of Intestinal Parasitic Infections and Related Risk Factors among Street Dwellers in Addis Ababa, Ethiopia. J Trop Dis 2: 132. doi:10.4172/2329-891X.1000132

Page 4 of 7

\begin{tabular}{|l|l|l}
\hline More than two years & $142(40.3)$ & $97(68.0)$ \\
\hline
\end{tabular}

Table 3: Prevalence of intestinal parasitic infections among the study participants by age groups, duration of stay as street dweller

\section{Intestinal parasitic infections and related risk factors}

The prevalence of intestinal parasitic infections was higher among individuals who had domestic animals $(82.4 \%)$ compared to those who had no domestic animals (71.7\%). The prevalence of intestinal parasitic infections (83.0\%) was also higher among street dwellers who get their food source from individual houses compared to those individuals who get their food from hotels (71.7\%). A higher prevalence was also observed among individuals who didn't have hand washing habit (72.4\%) than others (Table 4).

\begin{tabular}{|c|c|c|}
\hline Risk factors & Frequency (\%) & Prevalence of intestinal parasites $n(\%)$ \\
\hline Having domestic animals & $17(4.8)$ & $14(82.4)$ \\
\hline Have no domestic animals & $318(89.6)$ & $288(71.7)$ \\
\hline \multicolumn{3}{|l|}{ Source of water } \\
\hline Public tap & 89(26.3) & $70(78.7)$ \\
\hline Private tap & $249(73.1)$ & $174(69.9)$ \\
\hline \multicolumn{3}{|l|}{ Type of latrine } \\
\hline Near the shelter & $17(5.0)$ & $13(76.5)$ \\
\hline Common latrine & 130(38.5) & $95(73.1)$ \\
\hline Private latrine & 191(56.5) & 136(71.2) \\
\hline \multicolumn{3}{|l|}{ Hand washing habit before meal } \\
\hline Yes & $56(15.8)$ & $38(67.0)$ \\
\hline No & $272(76.6)$ & 198(73.0) \\
\hline \multicolumn{3}{|l|}{ Habit of cut nails } \\
\hline Yes & $54(15.2)$ & $37(68.5)$ \\
\hline No & $276(77.7)$ & $200(72.5)$ \\
\hline Source of food & $254(71.6)$ & 182(71.7) \\
\hline From hotel & $41(11.6)$ & $34(83.0)$ \\
\hline From individuals house & $41(11.6)$ & $27(66.0)$ \\
\hline Mixed ( from hotel, house, garbage) & & \\
\hline
\end{tabular}

Table 4: Prevalence of intestinal parasitic infections in relation to different risk factors among study participants

\section{Knowledge of the study participants about intestinal parasitic infections}

Knowledge of the study participants about intestinal parasites is summarized in Table 5. The majority $(67.1 \%)$ of the participants responded that they had no adequate information about intestinal parasitic infections. However, out of 106 (32.9\%) participants who had information, $49.4 \%$ suggested that intestinal parasites can be transmitted from one person to other person. About two thirds $(62.0 \%)$ of them responded that intestinal parasites can infect any individual, while most $(78.3 \%)$ of them responded that intestinal parasites are preventable.

\begin{tabular}{|c|c|c|}
\hline Characteristics & Response categories & Number (\%) \\
\hline Heard about intestinal parasites & $\begin{array}{l}\text { Yes } \\
\text { No }\end{array}$ & $\begin{array}{l}106(32.9) \\
216(67.1)\end{array}$ \\
\hline Cause of intestinal parasites $(n=106)$ & $\begin{array}{l}\text { Contaminated food } \\
\text { Contaminated water } \\
\text { Sexual contact }\end{array}$ & $\begin{array}{l}77(72.6) \\
14(13.2) \\
15(14.2)\end{array}$ \\
\hline Can intestinal parsites transmit $(n=106) ?$ & $\begin{array}{l}\text { Yes } \\
\text { No }\end{array}$ & $\begin{array}{l}63(49.4) \\
43(40.5)\end{array}$ \\
\hline
\end{tabular}


Citation: Banchiamlak Mekonnen, Berhanu Erko and Mengistu Legesse (2014) Prevalence of Intestinal Parasitic Infections and Related Risk Factors among Street Dwellers in Addis Ababa, Ethiopia. J Trop Dis 2: 132. doi:10.4172/2329-891X.1000132

Page 5 of 7

\begin{tabular}{|c|c|c|}
\hline Mode of transmission $(n=63)$ & $\begin{array}{l}\text { Direct contact } \\
\text { Sexual contact } \\
\text { Fecal contamination } \\
\text { Other }\end{array}$ & $\begin{array}{l}40(63.5) \\
16(25.4) \\
28(44.4) \\
22(34.9)\end{array}$ \\
\hline Intestinal parasites infect all age groups $(n=106)$ & $\begin{array}{l}\text { Yes } \\
\text { No }\end{array}$ & $\begin{array}{l}66(62.3) \\
40(37.7)\end{array}$ \\
\hline Do they have treatment $(n=106)$ ? & $\begin{array}{l}\text { Yes } \\
\text { No }\end{array}$ & $\begin{array}{l}84(79.2) \\
22(20.8)\end{array}$ \\
\hline Intestinal parasitic infection is preventable $(n=106)$ & $\begin{array}{l}\text { Yes } \\
\text { No }\end{array}$ & $\begin{array}{l}83(78.3) \\
23(21.7)\end{array}$ \\
\hline Preventive methods $(n=83$ ) & $\begin{array}{l}\text { Personal hygiene } \\
\text { Food hygiene } \\
\text { Drinking alcohol } \\
\text { Drinking kerosene } \\
\text { Drinking koso } \\
\text { Chewing chat \& eating garlic }\end{array}$ & $\begin{array}{l}57(68.7) \\
6(7.2) \\
20(24.1) \\
7(8.4) \\
13(15.7) \\
3(3.6)\end{array}$ \\
\hline
\end{tabular}

Table 5: Knowledge of the study participants (age over 18 years) about intestinal parasitic infections

Results from logistic regression analysis for any parasitic infection are summarized in Table 6. Consuming over left fruit was significantly

\begin{tabular}{|c|c|c|c|}
\hline Characteristics & Prevalence* $^{*}$ & Crude OR $(95 \% \mathrm{Cl})$ & Adjusted OR $(95 \% \mathrm{Cl})$ \\
\hline \multicolumn{4}{|l|}{ Sex } \\
\hline female & $76.70 \%$ & $1.3(0.63,2.83)$ & $1.3(0.47,2.68)$ \\
\hline male & 71.2 & Reference & Reference \\
\hline \multicolumn{4}{|l|}{ Age (year) } \\
\hline$<20$ & $76.4 \%$ & $1.6(0.74,3.55)$ & $2.2(0.76,6.54)$ \\
\hline $20-29$ & $70.6 \%)$ & $1.2(0.61,2.33)$ & $1.3(0.61,2.75)$ \\
\hline 30-39 & $73.60 \%$ & $1.4(0.66,2.92)$ & $1.4(0.63,3.23)$ \\
\hline $40+$ & $66.70 \%$ & Reference & Reference \\
\hline \multicolumn{4}{|c|}{ Having domestic animals } \\
\hline yes & $82.40 \%$ & $1.8(0.52,6.56)$ & $1.4(0.37,5.40)$ \\
\hline no & $71.30 \%$ & Reference & Reference \\
\hline \multicolumn{4}{|l|}{ Educational level } \\
\hline Illiterate & $73.60 \%$ & $1.6(0.62,4.30)$ & $1.2(0.40,3.60)$ \\
\hline Primary & $69.40 \%$ & $1.3(0.45,3.88)$ & $1.0(0.31,3.43)$ \\
\hline Secondary\& above & $63.20 \%$ & Reference & Reference \\
\hline \multicolumn{4}{|l|}{ Eating fruit } \\
\hline Yes & $85.70 \%$ & $2.5(1.02,6.22)$ & $2.9(1.02,8.29)$ \\
\hline No & $70.40 \%$ & Reference & Reference \\
\hline \multicolumn{4}{|l|}{ Hand washing habit } \\
\hline yes & $67.00 \%$ & Reference & Reference \\
\hline
\end{tabular}


Page 6 of 7

\begin{tabular}{|l|l|l|l|}
\hline No & $73.00 \%$ & $1.3(0.68,2.36)$ & $3.9(0.20,75.40)$ \\
\hline cutting nails & & & \\
\hline yes & $68.50 \%$ & Reference & Reference \\
\hline No & $72.50 \%$ & $1.2(0.64,2.28)$ & $2.9(0.14,58.21)$ \\
\hline Awareness about intestinal parasites & & & \\
\hline Yes & $71.60 \%$ & Reference & Reference \\
\hline No & $72.68 \%$ & $1.1(0.65,1.78)$ & $1.33(0.74,2.4)$ \\
\hline
\end{tabular}

Table 6: Factors associated with intestinal parasitic infections among study participants

N.B: ${ }^{\star}=$ Positive for any parasites

\section{Discussion}

The results of the present study showed high prevalence of intestinal parasitic infections among street dwellers in Addis Ababa which is slightly higher or comparable to the findings of previous studies among street dwellers in Gondar City, north west Ethiopia [13], in Philippines [19] and from Peru [20], while it is lower compared to the overall prevalence of intestinal parasitic infections reported from street children in Nepal [21]. In the present study, multiple intestinal parasitic infections were found and Ascaris lumbricoides being the predominant parasite followed by Trichuris trichiura, Taenia species, Giardia lamblia and Entamoeba histolytical dispar. High prevalence of ascariasis is a good indicator of improper fecal disposal, while that of giardiasis reflects use of poor water quality among the study participants. Previous study among street dwellers in Ethiopia showed high prevalence of Ascaris lumbricoides, followed by hookworms, Trichuris trichiura and Giardia lamblia [13]. A study conducted in Rio de Janeiro among 82 street dwellers living in the streets of Rio de Janeiro City, showed high prevalence of Ascaris lumbricoides followed by Trichuris trichiura and hookworms [22]. A study conducted in street children in Philippines also showed multiple intestinal parasitic infections including Ascaris lumbricoides, hookworms, Trichuris trichiura, Entamoeba histolytica, Giardia lamblia and Blastocystis hominis [19]. Multiple intestinal parasitic infections were also observed among street children in Argentina [23]. In the present study, the prevalence of Taenia species was considerably higher next to Ascaris lumbricoides and Trichuris trichiura, which is in contrast to the results of earlier study among street dwellers in other part of Ethiopia [23].

The overall prevalence of intestinal parasitic infections observed in this study also is comparable to the findings of various previous community/school children based studies in Ethiopia $[11,24,25]$. The proportion of infected female participants with intestinal parasites was slightly higher than the proportion of infected male participants. This finding is inconsistent with the result of previous study from Ethiopia [13]. Concerning the relation of age group and parasitic infection, the study revealed relatively a higher infection rate in the age group younger than 20 years. This indicates a common pattern of behavior and susceptibility to infection because of children has a habit of playing with soil and poor personal hygiene. Other study[23] also reported a high overall prevalence of intestinal parasitic infections in younger street children. Previous urban community based study in Ethiopia also showed high prevalence of intestinal parasitic infections in teenagers [24]. In the present study, relatively a higher infection rate was observed among illiterate, which is in agreement with the result of previous studies in Ethiopia $[9,13,26]$.

In general, street dwellers do not have access to latrine facilities and their excreta could be a potential source of soil, water and streetvended food contamination in the surroundings. In view of this, the present study indicated that some of the study subjects defecated on road-side opens space, drains and near the shelter and this practice of the street-dwellers could be potential source of contamination of soil, water and street-vended food which is hazards to health [8]. Hygiene depends on the availability of water like hand washing after defecation or before eating food seems like extravagance among street dwellers. The present study also revealed that considerable proportion of study participants do not wash their hands before meal (76.6\%), while hand washing can reduce the risk for infection with intestinal parasites.

In this study it was also noted that considerable number of street dwellers had no adequate information about intestinal parasitic infections which is similar to the results of previous study in other community [25]. This could be also other potential risk factor for intestinal parasitic infections.

In conclusion, the results of the present study showed high prevalence of intestinal parasitic infections among street dwellers in Addis Ababa and associated risk indicators which in turn could be a potential source of the contamination of soil, water and street-vended food in Addis Ababa. Unless the intestinal parasites prevention strategies consider these segments of the population in Ethiopia, they constitute major sources of intestinal parasitic infections for the community though further community-based prevalence study of intestinal parasitic infections is needed in Addis Ababa.

\section{Acknowledgements}

We thank the School of Graduate Studies and Aklilu Lemma Institute of Pathobiology, Addis Ababa University, for financial support. We thank Dr. Girmay Medhin for his sincere statistical advice and technical staff of the Medical Parasitology Research Unit for their cooperation during laboratory work. We also thank the study participants.

\section{References}

1. WHO Expert Committee (2002) Prevention and control of schistosomiasis and soil-transmitted helminthiasis. World Health Organ Tech Rep Ser 912: i-vi, 1-57, back cover.

2. Hwang SW (2000) Mortality among men using homeless shelters in Toronto, Ontario. JAMA 283: 2152-2157. 
Citation: Banchiamlak Mekonnen, Berhanu Erko and Mengistu Legesse (2014) Prevalence of Intestinal Parasitic Infections and Related Risk Factors among Street Dwellers in Addis Ababa, Ethiopia. J Trop Dis 2: 132. doi:10.4172/2329-891X.1000132

Page 7 of 7

3. Cheung AM1, Hwang SW (2004) Risk of death among homeless women: a cohort study and review of the literature. CMAJ 170: 1243-1247.

4. Morrison DS (2009) Homelessness as an independent risk factor for mortality: results from a retrospective cohort study. Int J Epidemiol 38: 877-883.

5. Zlotnick C1, Zerger S (2009) Survey findings on characteristics and health status of clients treated by the federally funded (US) Health Care for the Homeless Programs. Health Soc Care Community 17: 18-26.

6. Kushel MB1, Vittinghoff E, Haas JS (2001) Factors associated with the health care utilization of homeless persons. JAMA 285: 200-206.

7. Uddin MJ1, Koehlmoos TL, Ashraf A, Khan AI, Saha NC, et al. (2009) Health needs and health-care-seeking behaviour of street-dwellers in Dhaka, Bangladesh. Health Policy Plan 24: 385-394.

8. Uddin MJ (2010) Street dwellers preference for health care services in Dhaka, Bangladesh. Health Sci Bull 8: 6-11.

9. Tadesse G (2005) The prevalence of intestinal helminthic infections and associated risk factors among school children in Babile town, eastern Ethiopia. Ethiop J Health Dev 19: 140-7.

10. Erko B1, Medhin G (2003) Human helminthiasis in Wondo Genet, southern Ethiopia, with emphasis on geohelminthiasis. Ethiop Med J 41: 333-344.

11. Legessse M, Erko B (2004) Prevalence of intestinal parasites among schoolchildren in a rural area close to the southeast of Lake Langano, Ethiopia. Ethiop J Health Dev 18: 116-120.

12. Endeshaw T (2005) Opportunistic and other intestinal parasites among HIV/AIDS patients in Ethiopia. Dissertation paper 1-123.

13. Moges F1, Kebede Y, Kassu A, Degu G, Tiruneh M, et al. (2006) Infection with HIV and intestinal parasites among street dwellers in Gondar city, northwest Ethiopia. Jpn J Infect Dis 59: 400-403.

14. FMoH (2013) National Master Plan for Nelected Tropical Diseases (NTDS) 2013-2015. FMoH, Addis Ababa, Ethiopia.

15. UNICEF street dwellers in Addis Ababa.

16. CSA (2007) Central Statistical Agency of Ethiopia, Statistical Report of the 2007 Population and Housing Census. Addis Ababa, Ethiopia.
17. Cheesbrough M (2005) District laboratory practice in tropical countries, 2nd rev. ededn. London: Cambridge University Press: Tropical Health Technology.

18. Berhe N1, Medhin G, Erko B, Smith T, Gedamu S, et al. (2004) Variations in helminthfaecal egg counts in Kato-Katz thick smears and their implications in assessing infection status with Schistosomamansoni. Acta Trop 92: 205-212.

19. Baldo ET1, Belizario VY, De Leon WU, Kong HH, Chung DI (2004) Infection status of intestinal parasites in children living in residential institutions in Metro Manila, the Philippines. Korean J Parasitol 42: 67-70.

20. Bailey C1, Lopez S, Camero A, Taiquiri C, Arhuay Y, et al. (2013) Factors associated with parasitic infection amongst street children in orphanages across Lima, Peru. Pathog Glob Health 107: 52-57.

21. Ghimire TR (2010) Pattern of intestinal parasites at open air defecation sites in Kathmandu Valley, Nepal. Trop J Health Scie 17: 48-53.

22. Gomes TC1, Almeida MF, Miura LA, Granja J, Santos DV, et al. (2002) [Intestinal helminthiasis in street population of Rio de Janeiro city]. Rev Soc Bras Med Trop 35: 531-532.

23. Guignard S1, Arienti H, Freyre L, Lujan H, Rubinstein H (2000) Prevalence of enteroparasites in a residence for children in the Córdoba Province, Argentina. Eur J Epidemiol 16: 287-293.

24. Mengistu A, Gebre-Selassie S, Kassa T (2007) Prevalence of intestinal parasites among urban dwellers in South West Ethiopia. Ethiop J Health Dev 21: 12-17.

25. Nyantekyi LA, Legesse M, Belay M, Tadesse K, Manaye K, et al. (2010) Intestinal parasitic infections among under-five children and maternal awareness about the infections in SheshaKekele,Wondo Genet, Southern Ethiopia. Ethiop J Health Dev 24: 185-90.

26. Wördemann M1, Polman K, Menocal Heredia LT, Diaz RJ, Madurga AM, et al. (2006) Prevalence and risk factors of intestinal parasites in Cuban children. Trop Med Int Health 11: 1813-1820. 